\title{
Occurrence and outcome after primary treatment of anal fistulae in Crohn's disease
}

\author{
G HELLERS,* O BERGSTRAND, S EWERTH, AND B HOLMSTRÖM \\ From the Department of Surgery, Karolinska Institutet at Serafimerlasarettet, Stockholm, Sweden
}

SUMmaRY During the period 1955 to 1974 inclusive, 826 patients developed Crohn's disease and were registered citizens of Stockholm County at the time of definite diagnosis. These patients were followed up and investigated with reference to the occurrence of and outcome after treatment for anal fistulae. These fistulae were recorded in 184 patients $(23 \%)$. The incidence of anal fistulae increased the further distally the intestinal lesion was located. Healing followed local operation for anal fistula before curative intestinal resection in approximately $60 \%$ of the patients with small intestinal and combined ileocolic disease. However, patients with colonic Crohn's disease did not heal after such treatment. When curative intestinal resection was the primary procedure, $47 \%$ of the patients healed spontaneously. Small intestinal and combined ileocolic disease was associated with a good prognosis- $90 \%$ were healed at follow-up, while patients with colonic disease had a poor prognosis. The combination of rectal Crohn's disease and anal fistula invariably led to proctocolectomy.

Fistulae commonly occur in connection with Crohn's disease and are one of the many manifestations of this disease, rather than a complication. The frequency of anal fistulae in different series varies between 10 and $100 \% .{ }^{1-7}$ These major variations in frequency are apparently attributable to the occurrence of fistulae being related to the site of the intestinal lesion. Thus Crohn and Yarnis ${ }^{8}$ found anal lesions in $14 \%$ of patients with small intestinal disease, while Lockhart-Mummery' found such lesions in almost every patient with rectal Crohn's disease.

The treatment of anal fistulae associated with Crohn's disease is a major therapeutic problem. It has generally been stated that anal fistulae should not be treated surgically until the intestinal lesion has been resected. ${ }^{310} 11$

The aim of this study was to investigate the incidence of anal fistulae in an epidemiologically limited group of patients with Crohn's disease. The object was also to study the correlation between the incidence of anal fistulae and the site of the intestinal lesion and its influence on the outcome after surgical treatment.

-Address for correspondence: Dr G Hellers, Department of Surgery, Huddinge Hospital, S-141 86 Huddinge, Sweden.

Received for publication 15 November 1979

\section{Methods}

\section{PATIENTS}

The patients were those individuals who, during the 20 year period 1955 to 1974 inclusive, developed Crohn's disease and who at the time of definite diagnosis were registered citizens of Stockholm County.

The cases were collected by searching the diagnosis files of all hospitals in Stockholm County for the corresponding period of time. For operated patients, the scoring-table suggested by Lennard-Jones ${ }^{12}$ was used to establish the diagnosis. For patients not operated upon, typical symptoms and at least two unequivocal radiographs at an interval of at least three months were obligatory.

There were 826 patients- 379 males and 447 females. The age and sex distribution at time of diagnosis is given in Table 1 . The patients were followed up by structured interview and simultaneous reviewing of the case records. At follow-up, the site of the intestinal lesion at the time of definite diagnosis as well as the site and nature of all primary fistulae were recorded. The outcome after primary treatment of each fistula was also recorded.

The mean time of observation from diagnosis to follow-up was 9.4 years (range 0.5-22.5 years).

Additional details of collection, follow-up pro- 
Table 1 Age and sex distribution in 826 patients with Crohn's disease in Stockholm County 1955-74

\begin{tabular}{lcccccccccc}
\hline Sex & \multicolumn{1}{c}{ Age group (years) } & \multicolumn{10}{c}{ All ages } \\
& 0.9 & $10-19$ & $20-29$ & $30-39$ & $40-49$ & $50-59$ & $60-69$ & $70-79$ & $80-89$ \\
\hline Males & 6 & 92 & 140 & 56 & 34 & 28 & 17 & 5 & 1 & 379 \\
Females & 5 & 100 & 130 & 76 & 56 & 44 & 24 & 9 & 3 & 447 \\
Both & 11 & 192 & 270 & 132 & 90 & 72 & 41 & 14 & 4 & 826 \\
\hline
\end{tabular}

Table 2 Age and sex distribution in 184 patients with anal fistulae and Crohn's disease

\begin{tabular}{llllllllll}
\hline Sex & \multicolumn{1}{l}{ Age group (years) } \\
\cline { 2 - 9 } & $0-9$ & $10-19$ & $20-29$ & $30-39$ & $40-49$ & $50-59$ & $60-69$ & $70-79$ & $80-89$ \\
\hline Males & 1 & $29(32)$ & $55(39)$ & $20(36)$ & $11(32)$ & $7(25)$ & 2 & 0 & 0 \\
Females & 0 & $19(19)$ & $27(21)$ & $21(28)$ & $12(21)$ & $11(25)$ & 4 & 1 & 1 \\
\hline
\end{tabular}

In parentheses: the percentage of patients in each age-group in relation to the number of patients in the total material.

cedures, and data processing have been reported elsewhere. ${ }^{13}$

\section{Results}

Anal fistulae were recorded in $184 / 826(23 \%)$ of the patients.

\section{AGE AND SEX}

The age and sex distribution of the patients with fistulae is shown in Table 2. There were 125 males and 96 females. Thus $33 \%$ of the males and $22 \%$ of the females had fistulae. This difference is significant $(P<0.01$, exact probability test of Fisher). The age distribution of the patients with fistulae does not, however, differ from that of the whole patient group.

\section{FISTULAE AND TIME OF DEFINITE \\ DIAGNOSIS}

Patients were allocated into four groups according to when their fistulae appeared relative to the time of definite diagnosis: more than two years before diagnosis, between two years and six months before, six months before to three months after diagnosis, and after more than three months. There were $19,26,85$, and 91 patients respectively in the four groups.

FISTULAE AND SITE OF INTESTINAL LESION The frequency of anal fistulae in relation to the site of the intestinal lesion is given in Table 3 . It is apparent that the risk of developing anal fistulae increases the farther distally the intestinal lesion is located.

OUTCOME OF PRIMARY LOCAL TREATMENT

Among the $\mathbf{4 0}$ patients with small intestinal lesions only, 22 were submitted to local operation for anal fistulae before curative surgery for the intestinal lesion. Among these, eight (38\%) did not heal before curative surgery for the intestinal lesion was performed. The corresponding recurrence rate after local treatment in the 51 patients with combined ileocolic disease was $9 / 21$ (43\%). Fifty-six of 93 patients with large intestinal disease only were treated with local operation, and $46(83 \%)$ did not heal.

\section{OUTCOME AFTER PRIMARY CURATIVE RESECTION}

The outcome after primary curative intestinal resection is shown in Table 4. Spontaneous healing occurred in $20(47 \%)$ after resection of the intestinal lesions. However, in seven (35\%) of these patients the fistulae reopened within 2.5 years.

\section{STATUS AT FOLLOW-UP}

In the $\mathbf{4 0}$ patients with fistulae and small intestinal disease, 36 were healed at follow-up, three had an open fistula, and one patient had undergone proctocolectomy. However, in the healed 36 patients repeated local operations had been performed in many before healing.

Table 3 Frequency of fistulae in relation to site of intestinal lesion

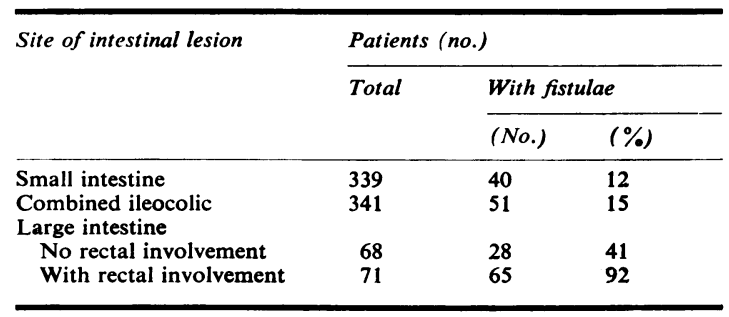


Table 4 Spontaneous healing of anal fistulae in relation to site of intestinal lesion after primary curative resection of the intestinal lesion

\begin{tabular}{llcl}
\hline Site of intestinal lesion & \multicolumn{2}{l}{ Patients (no.) } \\
\cline { 2 - 4 } & Total & Healed & Recurrence* $^{*}$ \\
\hline Small intestine & 14 & 9 & 4 \\
$\begin{array}{l}\text { Combined ileocolic } \\
\text { Large intestine }\end{array} \quad 25$ & 10 & 3 \\
$\quad$ No rectal involvement & 4 & 1 & 0 \\
\hline
\end{tabular}

* Recurrence: reopening of the fistula after primary spontaneous healing.

Among the 51 patients with combined ileocolic disease, 46 were healed, four had an open fistula, and one had undergone proctocolectomy.

Among the 28 patients with large intestinal disease without rectal involvement, eight were healed, seven had an open fistula, and 13 had undergone proctocolectomy.

Finally, among the 65 patients with rectal involvement, four were healed, three had an open fistula and 58 had undergone proctocolectomy.

\section{Discussion}

The incidence of anal fistulae in patients with Crohn's disease in the present study is similar to that reported in other series. ${ }^{7} 910$ Furthermore, the distribution of fistulae in different age groups is similar to that for all patients with the disease. This is worth noting, as one might have expected a higher incidence in younger age groups. In younger patients the disease is more active, and associated with more frequent surgery and earlier recurrence than in elderly patients..$^{13}$ In the present study, there is a significant difference in the incidence of anal fistulae between the two sexes. This has not been previously reported. There is no immediate explanation available for this difference. The present study also shows that the appearance of anal fistulae is usually closely related to the time of definite diagnosis. However, a few patients may develop fistulae long before the definite diagnosis, and sometimes in the absence of other symptoms of Crohn's disease.

As has been shown in other studies ${ }^{7}$ the incidence of fistulae increases the further distally the intestinal lesion is located.

It has been stated that local surgical treatment of anal fistulae is not advisable before resection of the intestinal lesion. ${ }^{\mathbf{1 1 0 1 1}}$ However, in the present study approximately $60 \%$ of patients with small intestinal or combined ileocolic disease healed after local surgery. Thus, local surgery is well worth trying in such patients when intestinal resection is not planned. In patients with colonic disease, however, local surgery is not followed by healing.

In almost $50 \%$ of patients, healing of anal fistulae occurred spontaneously after primary curative intestinal resection, although they recurred late in some. Thus, if curative resection is planned, local surgical treatment can, if feasible, be postponed in order to await possible spontaneous healing.

As the status at follow-up shows, the prognosis in patients with small intestinal and combined ileocolic disease is quite satisfactory; the majority of patients had healed. In patients with colonic disease, however, the prognosis is poor. The combination of rectal Crohn's disease and anal fistulae invariably leads to proctocolectomy. The poor prognosis for this group of patients might have been altered by a more frequent use of a diverting colostomy. However, as in the present study this procedure was seldom used, any possible benefit cannot be evaluated.

\section{References}

${ }^{1}$ Lockhart-Mummery HE, Morson BC. Crohn's disease of the large intestine. Gut 1964; 5: 493-509.

${ }^{2}$ Edwards H. Crohn's disease. $J$ Roy Coll Surg Edinb 1964; 9: 115-27.

${ }^{3}$ Edwards H. Crohn's disease: an inquiry into its nature and consequences. Ann Roy Coll Surg Engl 1969; 44: 121-39.

${ }^{4}$ Schofield PF. The natural history and treatment of Crohn's disease. Ann Roy Coll Surg Engl 1965; 36: 258-79.

${ }^{5}$ Alexander-Williams J. The place of surgery in Crohn's disease. Gut 1971; 12: 739-49.

${ }^{6}$ Alexander-Williams J. Surgery and the management of Crohn's disease. Clin Gastroenterol 1972; 1: 469-91. ${ }^{7}$ Fielding JF. Perianal lesions in Crohn's disease. $J$ Roy Coll Surg Edinb 1972; 17: 32-7.

${ }^{8}$ Crohn BB, Yarnis H. Regional ileitis, 2nd ed. New York: Grune and Stratton, 1958.

${ }^{\circ}$ Lockhart-Mummery HE. Anal lesions in Crohn's disease. Clin Gastroenterol 1972; 1: 377-82.

${ }^{10} \mathrm{Goligher}$ JC. Crohn's disease. In: Surgery of the anus, colon and rectum, 3rd ed. London: Baillière 1975: 1013-44.

${ }^{11}$ Weterman IT. Course and long-term prognosis of Crohn's disease. Leyden: Thesis, 1976.

${ }^{12}$ Lennard-Jones JE. Definition and diagnosis of Crohn's disease. In: Engel A, Larsson T, eds. Regional enteritis (Crohn's disease) (Skandia International Symposia 5). Stockholm: Nordiska Bokhandelns Förlag, 1971: 105-15.

${ }^{13}$ Hellers G. Crohn's disease in Stockholm County 19551974. Acta Chir Scand 1979; suppl 490. 